\title{
THE EFFECT OF CORTICOTROPHIN AND PREDNISOLONE ON INFANTILE SPASMS WITH MENTAL RETARDATION
}

\author{
BY \\ B. D. BOWER and P. M. JEAVONS \\ From the Department of Paediatrics and Child Health, University of Birmingham and \\ The Children's Hospital, Birmingham
}

(RECEIVED FOR PUBLICATION MAY 20, 1960)

The immediate effects of the use of corticotrophin or cortisone in patients with infantile spasms may be dramatic (Sorel and Dusaucy-Bauloye, 1958; Low, 1958; Sorel, 1959), but the more permanent results are less easily assessed. There is still no confirmation of Sorel's claims that corticotrophin can produce prolonged benefit, in particular mental improvement, for long-term improvement can occur without such treatment. This paper reports an attempt to assess the immediate and later results of treatment with corticotrophin and prednisolone by comparison with the findings in patients not treated with hormones (Jeavons and Bower, 1961).

\section{Material and Method}

Twenty-three children with infantile spasms have been treated with corticotrophin or prednisolone or both. Of these, 21 were treated personally. E.E.G. examinations of the remaining two, who were treated by Drs. J. S. Oldham and H. McC. Giles, were performed in our departments and their records have been assessed in the same way as those of our patients. All patients had an abnormal E.E.G. before treatment and all were mentally retarded.

Twelve patients are classified as belonging to the cryptogenic group. Mental development was normal until the onset of the epilepsy and in 11 there was no clue to the cause of the cerebral damage. In the twelfth patient, spasms started three days after his first injection of poliomyelitis vaccine, but since the relevance of this event to the disorder is uncertain, he is included in this group.

The other 11 patients are classified in the symptomatic group. Mental retardation was present from birth and there was evidence suggesting a definite cause for cerebral damage (Table 1). In 10 cases the cause was a perinatal factor or combination of factors, while in one it was cerebral agenesis with absence of the corpus callosum. In one patient spasms had already ceased before treatment but, as he was mentally retarded and his E.E.G. was still abnormal, treatment was given and his case is included.
All patients were treated in hospital for at least four weeks. If E.E.G. improvement was still occurring at the end of that time, treatment was continued until a steady state was reached. Eight patients were given a second month's treatment because relapse followed the first course or because the first course was ineffective. In one instance a third course was given, as an outpatient. With the exception of the first two cases treated and one very young patient, the daily dose of corticotrophin was 20-30 units, according to age. The drug

TABLE 1

SYMPTOMATIC GROUP

FACTORS LEADING TO DIAGNOSIS OF PRENATAL OR PERINATAL BRAIN DAMAGE

\begin{tabular}{|c|c|c|c|}
\hline Case & History & $\begin{array}{l}\text { Micro- } \\
\text { cephaly }\end{array}$ & Other Evidence \\
\hline S.1 & $\begin{array}{l}\text { Pitocin drip, precipitate } \\
\text { labour }\end{array}$ & Yes & - \\
\hline S.2 & - & No & $\begin{array}{l}\text { Cerebral agenesis with } \\
\text { absence of corpus } \\
\text { callosum (pneumo- } \\
\text { encephalography) }\end{array}$ \\
\hline S.3 & $\begin{array}{l}\text { Precipitate labour; spasms } \\
\text { from second day }\end{array}$ & Yes & Cerebral diplegia \\
\hline S.4 & $\begin{array}{l}\text { Premature (birth weight } \\
\quad 3 \mathrm{lb} .5 \mathrm{oz} .)\end{array}$ & Yes & - \\
\hline S.5 & $\begin{array}{l}\text { Caesarean section for } \\
\text { foetal distress; neo- } \\
\text { natal cyanotic attacks }\end{array}$ & Yes & - \\
\hline S.6 & $\begin{array}{l}\text { Antepartum haemor- } \\
\text { rhage, foetal distress }\end{array}$ & Yes & $\begin{array}{l}\text { Symmetrical ventricular } \\
\text { dilatation (pneumo- } \\
\text { encephalography) }\end{array}$ \\
\hline S.7 & $\begin{array}{l}\text { Prolonged labour; neo- } \\
\text { natal cyanosis }\end{array}$ & No & Hemiparesis \\
\hline S.8 & $\begin{array}{l}\text { Premature; } \\
\text { 'jumps' and cyanotic } \\
\text { attacks; did not cry } \\
\text { for three weeks }\end{array}$ & Yes & - \\
\hline S.9 & $\begin{array}{l}\text { Neonatal hypotonia; } \\
\text { would not cry or suck } \\
\text { for six weeks }\end{array}$ & No & - \\
\hline S.10 & $\begin{array}{l}\text { Drowsiness and failure } \\
\text { to suck in neonatal } \\
\text { period }\end{array}$ & Yes & - \\
\hline S.11 & $\begin{array}{l}\text { Forceps delivery; head } \\
\text { bruised }\end{array}$ & No & Mild hemiparesis \\
\hline
\end{tabular}


was given 12 hourly by injection, in the gel form. Prednisolone was given six hourly by the oral route, the daily dose being approximately $1 \mathrm{mg}$. per lb. body weight. In a few instances the dose was altered later in the course, and at the end of treatment reduction was made gradually. Details of treatment are shown in Tables 2 and 3.

Progress was judged in three parameters. The spasms were charted by the nursing staff. Although some may have occurred unnoticed, these were probably few, for there is a good correlation between the presence or absence of spasms as charted and the E.E.G. state. Moreover, spasms usually occur in a series lasting several minutes and the initial cry often draws the attention of the nurse to the event. Nevertheless, we shall consider them as 'present', 'fewer' or 'absent', rather than by numbers recorded.

E.E.Gs were recorded twice weekly during hospital stay and as often as was convenient after discharge. At the beginning of the study they were scored in a random order by one of us (P.M.J.) with no knowledge of the patient's treatment at the time. Later, with increased confidence in the method, records were scored as treatment proceeded, in order to help in deciding the length of treatment necessary in each case. The scoring system is described elsewhere (Jeavons and Bower, 1961). In all, 481 E.E.G. records were taken. Mental assessment was performed by Griffiths testing before treatment, within three weeks after stopping treatment, and at intervals during the follow-up period.
Results: The Cryptogenic Group (12 cases)

The Immediate Results. These are shown in detail in Table 2 .

Spasms. These ceased in all patients during the first course of treatment, whichever drug was used. In five this occurred during the first week, but in two patients it did not occur until more than five weeks of treatment had been given. One patient (C. 12) who had major fits in addition to spasms, continued with intermittent major fits during treatment despite control of spasms and, on withdrawal, developed status epilepticus.

Relapse occurred in eight patients within three weeks of stopping treatment, usually within the first week.

E.E.G. There was also a definite E.E.G. improvement in all patients during the first course of treatment. In 11 the score fell and reached 4 or less (i.e. non-hypsarrhythmic). In the twelfth (C. 5) the initial record was highly organized and scored only 2 . Her records were therefore assessed by counting the percentage of the total recording time which was occupied by epileptic activity. This fell from $65 \%$ before treatment to $10 \%$ during treatment.

TABLE 2

CRYPTOGENIC GROUP: TREATMENT AND IMMEDIATE RESULTS

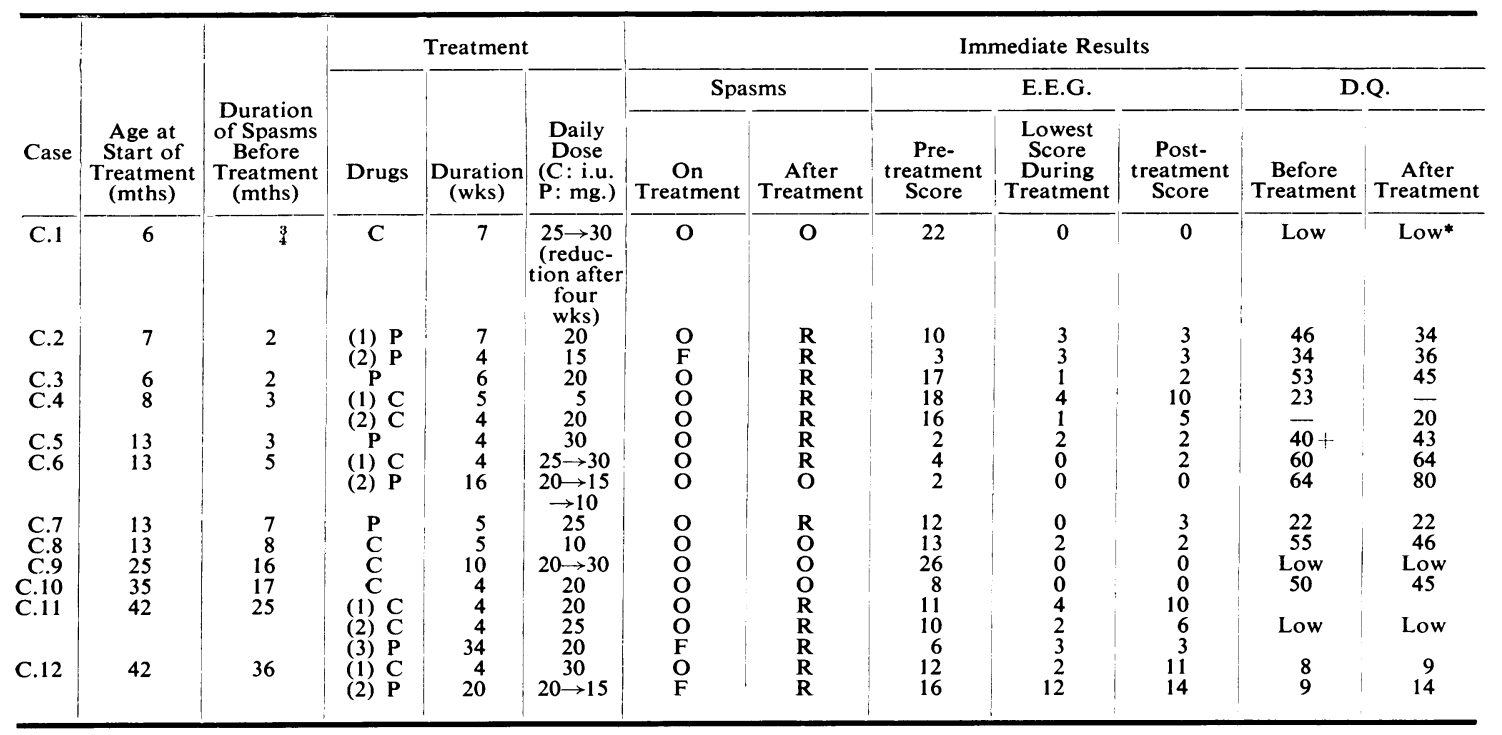

$\mathrm{C}=$ Corticotrophin

$\mathrm{O}=$ No spasms

$\mathbf{P}=$ Prednisolone

$\mathrm{F}=$ Fewer spasms than before treatment

$\mathbf{R}=$ Relapse after treatment

* This child subsequently reached 83 . 


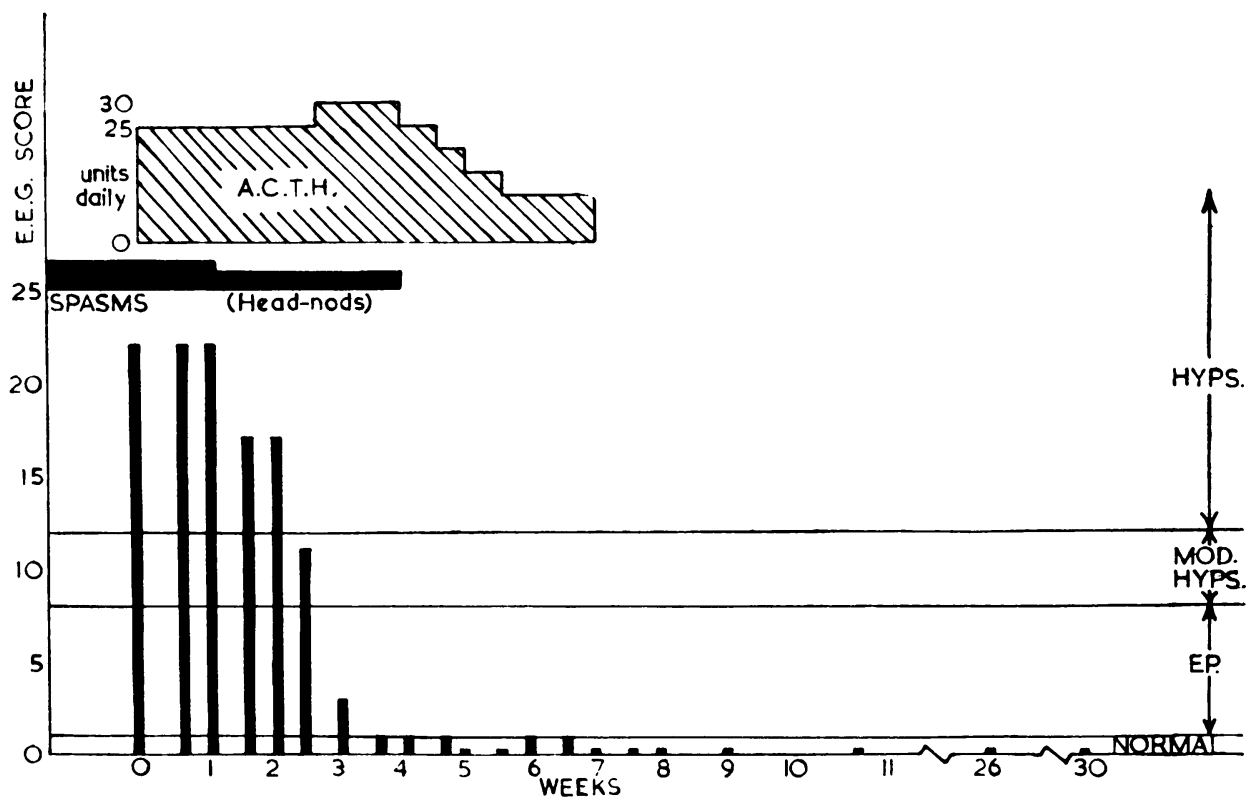

FIG. 1.-Response of spasms and E.E.G. to corticotrophin (patient C.1).

A record showing no epileptic activity (score 0 or 1) was obtained in six patients, and three of these showed completely normal records during the remainder of the course.

In only one patient did all epileptic abnormality disappear within the first week. In four the score was 3 or less before the end of the second week. There was no constant relationship between cessation of spasms and the E.E.G. score at that time. Sometimes spasms ceased before marked E.E.G. improvement occurred but at other times E.E.G. improvement preceded cessation of the spasms. However, the two events usually occurred within one week of each other. The time taken to achieve a non-epileptic record varied from seven to 64 days, and the speed of response was unrelated to the daily dose or the drug used. Fig. 1 shows a satisfactory response to corticotrophin, and Fig. 2 a similar but less complete response to prednisolone in another patient.

The E.E.G. improvement took the following form: First there was a gradual reduction in chaos, then a more normal activity emerged, with episodic bursts of chaotic wave-and-spike activity; then the epileptic discharges became more organized and tended to be bilateral, and slow wave-and-spike activity at $2 \mathrm{c}$. $/ \mathrm{sec}$. appeared. At this point there was a tendency for unilateral abnormality to appear and some records showed focal spiking, most commonly in the temporal regions. Many records continued to show bilaterally synchronous epileptic discharges, and only a few became normal.

In seven patients there was a deterioration after treatment was stopped, but in one of these (C. 6) there was no deterioration after a second course.

(This course was unusually long but the daily dose was low for much of the time.)

Mentality. There was no immediate dramatic mental improvement. In eight patients comparison of development quotients (D.Q.s), estimated before and within three weeks after treatment, showed no significant improvement. A ninth patient showed no improvement between an initial score and the score obtained after a second course of treatment (no test was performed between the first and second courses). In the remaining three, where only clinical assessment was used, again no improvement was observed. In several instances there was an apparent improvement; the child became livelier, sat up for the first time, or showed some other ability which was previously absent. However, full developmental testing showed no all-round improvement and the score remained at approximately the same figure. Probably the apparent advancement merely represented steroid euphoria. In four patients the score actually fell. 


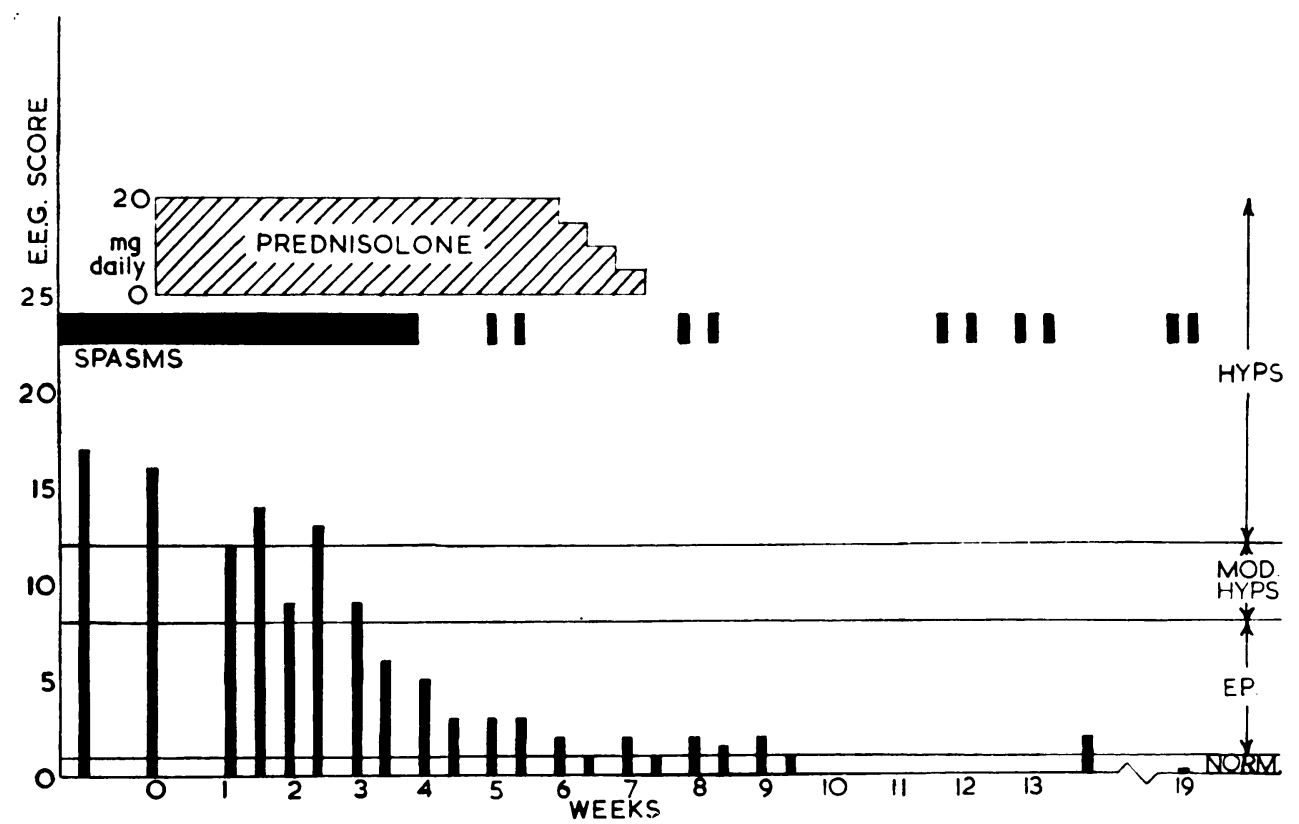

FIG. 2.-Response of spasms and E.E.G. to prednisolone (patient C.3).

Later Results. Five of the patients who relapsed after the first course were given another course of corticotrophin or prednisolone, and one received a third. In only one patient (C.6) was another course more successful than the first in preventing a recurrence. This child also showed a significant mental improvement, in contrast to the others. Her second course was prolonged, lasting 16 weeks.

The period of follow-up varies from three to 14 months from the start of treatment, the average being eight months. During follow-up two more patients became free of spasms (C.5 and 7), making a total of seven who have lost their spasms.

Mental progress was assessed by Griffiths testing in 10 cases (Fig. 3). In seven there was no significant improvement (an increase of more than $10 \%$ over the pre-treatment score). Two of the remaining three patients (C.1 and 6) have achieved a D.Q. of 80 . Unfortunately one of them (C.1) was not assessed by Griffiths testing before treatment but he was obviously retarded and, from questioning, it appeared that his D.Q. was probably between 50 and 60 . The initial score of the other (C.6) was 60 and it rose to 80 after the second course of treatment. Four months later there had been no further rise. Both these patients were free of spasms and their E.E.G.s remained normal after treatment. The third patient (C.8) has shown an advance of 11 points, to reach 6612 months after starting treatment. He also has had no spasms after treatment but his E.E.G. still shows a mild epileptic abnormality (score 2). The two patients not assessed by Griffiths testing, judged clinically, have shown no mental improvement.

In summary, the immediate results were dramatic as regards cessation of spasms and E.E.G. improvement but, after cessation of treatment, spasms recurred in eight patients and the E.E.G. deteriorated in seven. Only one of these eight patients did not relapse after a second course of treatment. After an average follow-up period of eight months, seven patients are free from spasms. The influence of treatment upon mental retardation has been disappointing. Only three patients have achieved an increase in D.Q. of more than $10 \%$ during the follow-up period and in no patient was this improvement immediate.

Results: The Symptomatic Group (11 patients)

The Immediate Results. These are shown in detail in Table 3.

SPASms. These ceased during the first course of treatment in only six patients, but in three others they became fewer. Only one patient was uninfluenced by treatment. The remaining patient (S.9) had already lost his spasms before treatment 


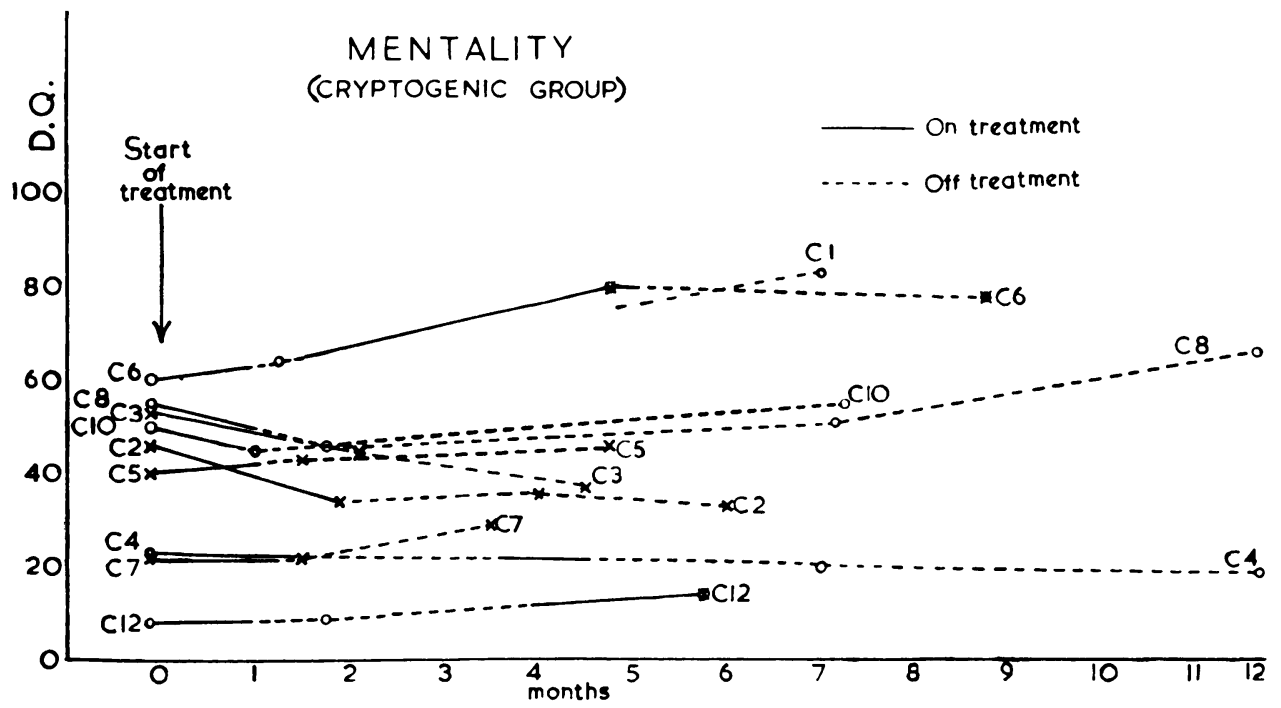

FIG. 3.-Mentality (D.Q.) during follow-up (10 patients in the cryptogenic group). $\quad O=$ treated with corticotrophin; $X=$ treated with prednisolone.

was started. Relapse occurred in seven patients, one maintained relative improvement, and only one patient achieved complete freedom from spasms after the course. Recurrence occurred within one week of stopping treatment in three patients and within four weeks in the other four.

E.E.G. There was an improvement during treatment in 10 of the 11 patients. Frank hypsarrhythmia was abolished, although the lowest score of one patient was in the 'modified hypsarrhythmia' range. A non-epileptic record (score 0 or 1 ) was achieved in three patients. Improvement took the same form as it did in the cryptogenic group.

Deterioration after treatment was stopped occurred in 10 patients.

Mentality. There was no significant improvement in any patient. This is not unexpected, in view of the fact that these patients had suffered

TABLE 3

SYMPTOMATIC GROUP: TREATMENT AND IMMEDIATE RESULTS

\begin{tabular}{|c|c|c|c|c|c|c|c|c|c|c|c|c|}
\hline \multirow[b]{3}{*}{ Case } & \multirow[b]{3}{*}{$\begin{array}{c}\text { Age at } \\
\text { Start of } \\
\text { Treatment } \\
\text { (mths) }\end{array}$} & \multirow{3}{*}{$\begin{array}{c}\text { Duration } \\
\text { of } \\
\text { Spasms } \\
\text { Before } \\
\begin{array}{c}\text { Treatment } \\
\text { (mths) }\end{array}\end{array}$} & \multicolumn{3}{|c|}{ Treatment } & \multicolumn{7}{|c|}{ Immediate Results } \\
\hline & & & \multirow[b]{2}{*}{ Drugs } & \multirow[b]{2}{*}{$\underset{\text { (wks) }}{\text { Duration }}$} & \multirow[b]{2}{*}{$\begin{array}{l}\text { Daily } \\
\text { Dose } \\
\text { (C: i.u. } \\
\text { P: mg.) }\end{array}$} & \multicolumn{2}{|c|}{ Spasms } & \multicolumn{3}{|c|}{ E.E.G. } & \multicolumn{2}{|c|}{ D.Q. } \\
\hline & & & & & & $\stackrel{\text { On }}{\text { Treatment }}$ & $\begin{array}{c}\text { After } \\
\text { Treatment }\end{array}$ & $\begin{array}{l}\text { Pre- } \\
\text { treatment } \\
\text { Score }\end{array}$ & \begin{tabular}{|c|} 
Lowest \\
Score \\
During \\
Treatment \\
\end{tabular} & $\begin{array}{c}\text { Post- } \\
\text { treatment } \\
\text { Score }\end{array}$ & $\begin{array}{c}\text { Before } \\
\text { Treatment }\end{array}$ & $\begin{array}{c}\text { After } \\
\text { Treatment }\end{array}$ \\
\hline $\begin{array}{l}\text { S.1 } \\
\text { S.2 }\end{array}$ & $\begin{array}{l}5 \\
2 \frac{1}{2}\end{array}$ & 4 days & (1) ${ }^{\mathrm{C}} \mathrm{P}$ & $\begin{array}{l}8 \\
3 \\
4\end{array}$ & $\begin{array}{r}25 \rightarrow 30 \\
12 \cdot 5 \\
25\end{array}$ & $\underset{\mathrm{U}}{\mathrm{O}}$ & $\begin{array}{l}\mathbf{R} \\
\mathbf{R}\end{array}$ & $\begin{array}{r}7 \\
6 \\
13\end{array}$ & $\begin{array}{l}0 \\
6 \\
3\end{array}$ & $\begin{array}{l}2 \\
9 \\
6\end{array}$ & $\begin{array}{c}35 \\
\text { Low }\end{array}$ & $\begin{array}{c}33 \\
\text { Low }\end{array}$ \\
\hline S.3 & 2 & 2 & $\begin{array}{l}\text { (1) } \mathrm{C} \\
\text { (2) } \mathrm{P}\end{array}$ & $\begin{array}{l}2^{*} \\
6\end{array}$ & $\stackrel{5}{7}+5 \rightarrow 10$ & $\begin{array}{l}\mathrm{F} \\
\mathrm{O}\end{array}$ & $\begin{array}{l}\mathrm{F} \\
\mathrm{R}\end{array}$ & $\begin{array}{l}14 \\
12\end{array}$ & 2 & $\begin{array}{r}12 \\
7\end{array}$ & Low & Low \\
\hline $\begin{array}{l}\text { S.4 } \\
\text { S.5 }\end{array}$ & $\begin{array}{l}9 \\
6\end{array}$ & $\begin{array}{l}2 \\
3\end{array}$ & (1) C & $\begin{array}{l}6 \\
4 \\
4\end{array}$ & $15 \rightarrow_{25}^{20}$ & $\begin{array}{l}\mathrm{F} \\
\mathrm{O}\end{array}$ & $\begin{array}{l}\mathbf{R} \\
\mathbf{R} \\
\mathbf{R}\end{array}$ & $\begin{array}{l}15 \\
16 \\
15\end{array}$ & $\begin{array}{l}9 \\
5 \\
4\end{array}$ & $\begin{array}{r}14 \\
7 \\
17\end{array}$ & $\begin{array}{l}35 \\
33 \\
25\end{array}$ & $\begin{array}{l}28 \\
31 \\
\end{array}$ \\
\hline $\begin{array}{r}\text { S.6 } \\
\text { S.7 } \\
\text { S.8 } \\
\text { S.9 } \\
\text { S.10 } \\
\text { S.11 }\end{array}$ & $\begin{array}{r}12 \\
8 \\
16 \\
13 \\
21 \\
50\end{array}$ & $\begin{array}{r}5 \\
6 \\
10 \\
15 \\
41\end{array}$ & $\begin{array}{l}\mathrm{C} \\
\mathrm{C} \\
\mathrm{P} \\
\mathrm{P} \\
\mathrm{P} \\
\mathrm{P}\end{array}$ & $\begin{array}{r}4 \\
4 \\
10 \\
4 \\
4 \\
4 \\
4\end{array}$ & $\begin{array}{c}25 \\
10 \underset{\rightarrow 20}{20} \\
20 \\
20 \\
40\end{array}$ & $\begin{array}{l}\mathrm{r} \\
\mathrm{O} \\
\mathrm{O} \\
\mathrm{F} \\
\mathrm{O} \\
\mathrm{O}\end{array}$ & $\begin{array}{l}\mathbf{K} \\
\mathbf{R} \\
\mathrm{O} \\
\mathrm{R} \\
\mathrm{R} \\
\mathrm{R}\end{array}$ & $\begin{array}{r}13 \\
9 \\
21 \\
17 \\
6 \\
12 \\
15\end{array}$ & $\begin{array}{l}4 \\
2 \\
1 \\
6 \\
0 \\
2 \\
4\end{array}$ & $\begin{array}{r}10 \\
1 \\
14 \\
2 \\
10 \\
10\end{array}$ & $\begin{array}{c}12 \\
12 \\
32 \\
4 \\
14 \\
2 \\
\text { Low }\end{array}$ & $\begin{array}{c}\text { Lower } \\
2 \\
21 \\
6 \\
20 \\
2 \\
\text { Low }\end{array}$ \\
\hline
\end{tabular}

$\mathrm{C}=$ Corticotrophin

$\mathrm{O}=$ No spasms

$\mathbf{P}=$ Prednisolone

$F=$ Fewer spasms than before treatment

$\mathbf{R}=$ Relapse

$\mathbf{U}=$ Unchanged

* Developed cardiac failure. 


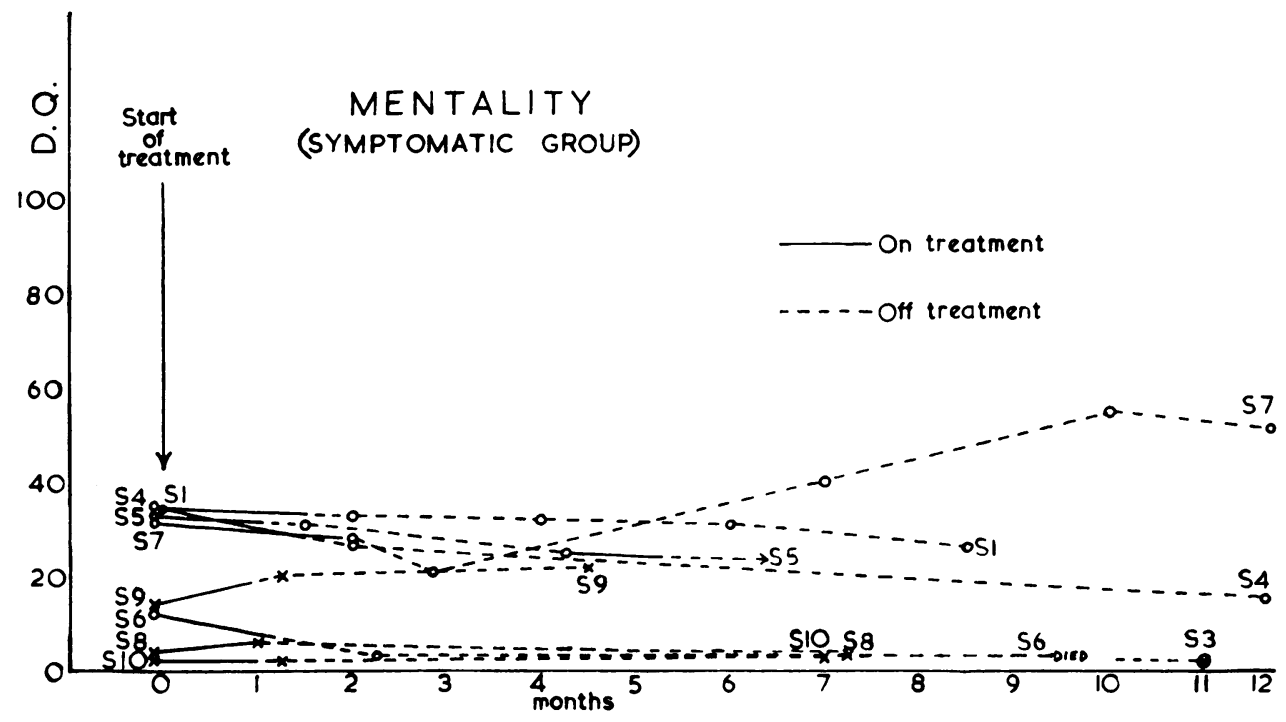

FIG. 4.-Mentality (D.Q.) during follow-up (nine patients in the symptomatic group). $\quad O=$ treated with corticotrophin; $X=$ treated with prednisolone.

brain damage at or before birth; seven were microcephalic and marked cerebral atrophy was demonstrable in another.

Later Results. Three patients were given a second course of treatment, using the alternative drug. In all three cases, although there was a response, a clinical and E.E.G. relapse occurred after the second course similar to that after the first (Fig. 5).

The period of follow-up (10 patients) varied from four months to 12 months from the start of treatment, the average again being eight months. Spasms stopped in two patients during this period, making a total of four free from spasms. The E.E.G. showed an increase in score after treatment and, although in some patients there has been a reduction of score since then, only one patient (S.7) has had a non-epileptic record since treatment. One patient (S.6) had been unable to attend for E.E.G. examination since six weeks after treatment was stopped but his E.E.G. score then was as high as it had ever been. He has since died.

Mental progress was assessed by Griffiths testing in nine patients (Fig. 4). Only one patient (S.7) has shown an increase in D.Q. of more than $10 \%$. He has only reached $52 \%$ but his performance is handicapped by a mild hemiparesis. $\mathrm{He}$ is the only patient whose epileptic and E.E.G. improvement was sustained after treatment. His treatment lasted longer than that of any other patient in the symptomatic group, although in the first months the daily dose was lower than the usual dose given. The remaining two patients, judged clinically, have shown no mental advance. One is a spastic ament. The other is aged $4 \frac{1}{2}$ years with a mental age of about 9 months.

In summary, the immediate results were qualitatively similar to, but not as dramatic as, those of the cryptogenic group. Spasms ceased during treatment in six patients and became fewer in three, and the E.E.G. improved in every patient but one. With one exception, relapse occurred in all patients after treatment, and relapse followed a second course given to three patients. After an average follow-up period of eight months, four patients are free from spasms. As expected, there was no overall mental improvement. One patient, however, has shown an increase in D.Q. of more than $10 \%$ during follow-up but he is still definitely retarded.

\section{Discussion}

Immediate Effects. From our results we agree with Sorel and Dusaucy-Bauloye (1958), Sorel (1959), Low (1958, 1959), Gastaut, Saltiel, Raybaud, Pitot and Meynadier (1959), Dumermuth (1959) and Stamps, Gibbs, Rosenthal and Gibbs (1959) that corticotrophin abolishes or greatly reduces the frequency of infantile spasms and improves the 
E.E.G., even to the point of normality. Cortisone has been credited with a similar effect (Low, 1958; Cox and Martin, 1959; and Dumermuth, 1959). Since prednisolone has a smaller salt-retaining effect than cortisone or corticotrophin, we decided to use it to treat some patients in order to compare its effects with those of corticotrophin, for if it was as successful as the other two drugs, it would have obvious advantages. Our results show that it has an effect similar to corticotrophin. A detailed comparison is made below. Disregarding for the moment any differences in the efficacy of the two drugs and considering the overall effect of hormone treatment, we see that spasms ceased in $81 \%$ of patients during treatment. The E.E.G. improved in $95 \%$, becoming non-epileptic in $39 \%$. The pattern of improvement was similar to that of the untreated series (Jeavons and Bower, 1961), but the improvement occurred in a matter of three to four weeks in the treated cases whereas it took months or years in the untreated cases.

Relapse after Treatment. Most of the above authors describe cases who relapse after treatment, but regard them as infrequent. By contrast, such cases form the majority in our series. Fifteen of our 21 patients whose spasms diminished or stopped during treatment relapsed within three weeks after treatment, whereas Sorel (1959) found a relapse in only two out of 10 patients treated with corticotrophin and Stamps et al. (1959) found a relapse in nine out of 36 who responded.

Since the tendency to relapse is greater in the symptomatic than in the cryptogenic group, one explanation of this difference might be that the above authors' series contained a higher proportion of cryptogenic cases than ours. Unfortunately, precise aetiological classification of their patients is difficult. However, the relapse rate is higher in our series, even if we only consider the cryptogenic group (eight out of 12). Another possibility is that our patients were treated at a later stage of the disease. Sorel (1959), Gastaut et al. (1959) and Low $(1958,1959)$ all consider that the earlier treatment is given, the better will be the results. Three of Sorel's patients started treatment within one month of onset, and two of ours did so. The average period between onset and treatment was eight months in Sorel's cases, and 10 months in ours. (Information is insufficient to allow comparison of our cases with those of the other authors.) It seems unlikely that the difference in results can be explained on the basis of such slight differences in timing of treatment. Nor does an age factor account for it, for the average ages of Sorel's patients and ours are similar. We usually gave

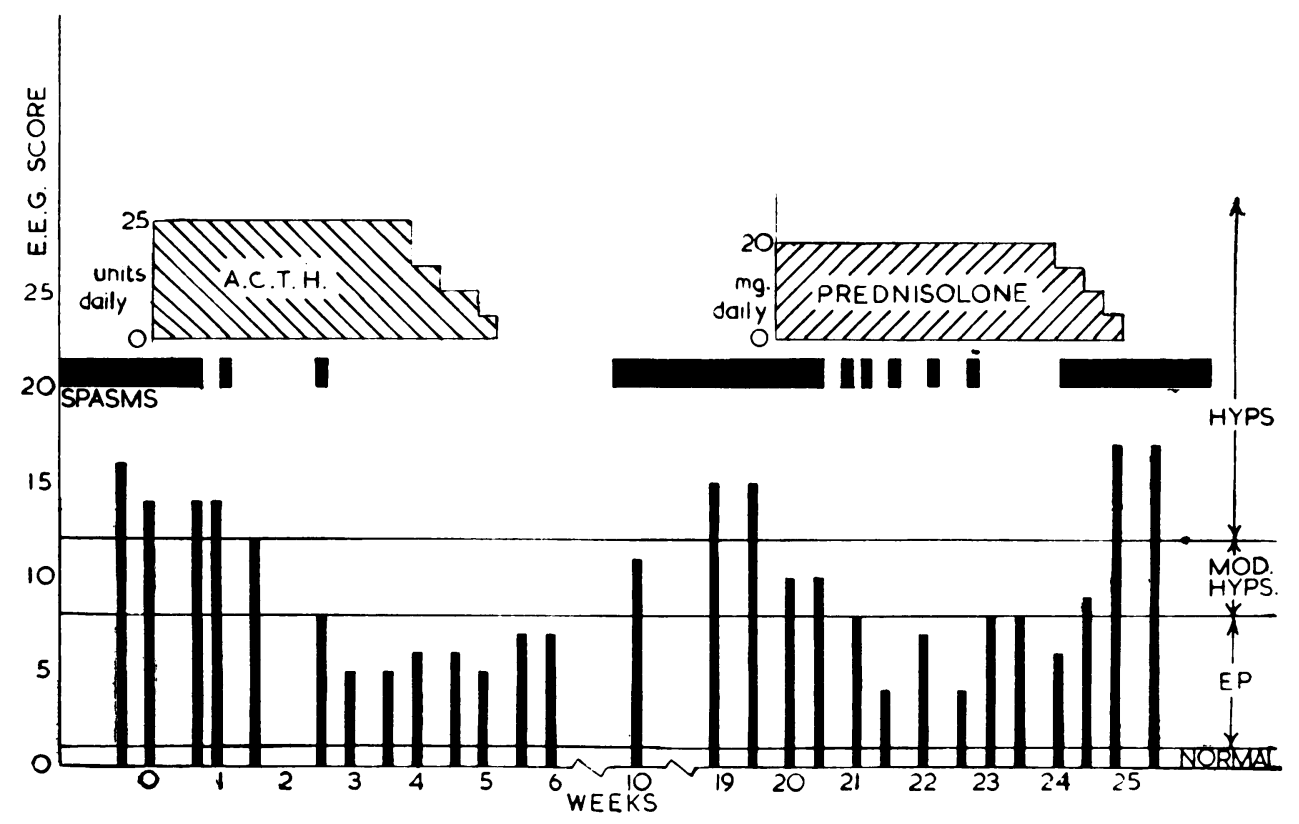

FIG. 5.-Response to corticotrophin and to prednisolone (patient S.5). 
a larger dose of corticotrophin than Sorel did and treatment was at least twice as long, so that our treatment was more than adequate by his standards. A possible explanation of the overall relapse rate is that prednisolone is less efficient in preventing a relapse than corticotrophin, which was the only drug used by Sorel. The two drugs are compared below.

Later Effects. Although our follow-up is as yet short (average eight months) it is interesting to try to assess whether treatment has long-term effects, or whether later improvement in the epilepsy is entirely due to the natural tendency to improve with age. In order to eliminate the immediate effect of treatment, we shall only consider patients who have been off treatment for more than three months. At the age of 12 months there were five such patients. Three of these had no spasms. At 18 months there were six such patients, and four had no spasms. In our series of untreated patients only three out of 29 had no spasms at 12 months and only six out of 29 at 18 months. Although numbers are small, this comparison suggests that the treatment had a prolonged beneficial effect on the epilepsy, and this suggestion is borne out by a consideration of E.E.G. scores. At 12 months, three of the five treated patients had non-epileptic records, by comparison with none of the 25 untreated patients, and at 18 months, two of the six treated patients had nonepileptic records, by comparison with three out of 24 in the untreated group.

Comparison of Corticotrophin with Prednisolone. There are obvious difficulties in comparing two drugs with a similar effect when patients differ in age, and their epilepsy differs in severity, aetiology and duration. However, such a comparison is justified in our series because the patients in each treatment group have the same average age (16 months), similar average durations of symptoms (nine and 10 months) and are equally distributed between the cryptogenic and symptomatic groups.

Both drugs were equally effective in controlling spasms during treatment. Considering first courses only, 12 out of 14 patients treated with corticotrophin lost their spasms, compared with six out of eight given prednisolone. However, there was a much higher relapse rate after prednisolone than after corticotrophin. All six patients whose spasms stopped during prednisolone treatment relapsed afterwards, whereas only seven of the 12 who responded to corticotrophin did so. Corticotrophin was also more effective in producing a normal E.E.G. Seven out of 14 treated with corticotrophin achieved a non-epileptic record, compared with two out of eight treated with prednisolone. The main difference was in the cryptogenic group. Fig. 5 illustrates the similar response to each drug shown by a patient in the symptomatic group.

We conclude, therefore, that corticotrophin is in general a little more effective than prednisolone. However, this conclusion refers only to the doses used by us. It is possible that a higher dose of prednisolone than $1 \mathrm{mg}$. per $\mathrm{lb}$. body weight per day would have achieved better results, although this is the usual dose employed in paediatric practice to obtain maximal effects. We have some evidence that the amount of endogenous adrenal steroid produced by patients given corticotrophin differed little from the amount of exogenous steroid given to prednisolone-treated patients. The daily urinary output of 17-hydroxycorticosteroids was estimated weekly in nine of the corticotrophin-treated patients. The maximal output was found to be between 10 and 20 times the basal output. This is evidence of adequate adrenal response, approximating to the dose of prednisolone given to the prednisolonetreated group. It is not possible to compare more accurately the quantities of steroids available from these exogenous and endogenous sources.

Mentality. Mental retardation is the most disabling feature of the clinical syndrome and the claim of Sorel (1959) that it can be abolished by corticotrophin is of paramount importance. Assessment of mental improvement is, of course, often difficult in these very young patients and all publications are inadequate in the data given. Except where a child is said to be normal, it is difficult to judge how much improvement has occurred. It was for this reason that we decided to attempt more precise assessment of mental improvement by using Griffiths testing.

It will be seen (Figs. 3 and 4) that initial scores are, in general, lower in the symptomatic group than in the cryptogenic group. Indeed, there are four in the symptomatic group who score less than 20 compared with one such patient in the cryptogenic group. This confirms our clinical assessment that patients in the symptomatic group tend to be more severely retarded (Jeavons and Bower, 1961).

No patient showed a significant increase in score immediately after the first course of treatment. We cannot therefore confirm the statements of Sorel and Dusaucy-Bauloye (1958) and Gastaut et al. (1959) that rapid mental improvement occurs in some patients. In several instances the scores actually fell. Occasionally a child appeared more alert or showed some new ability, but testing 
after the course showed no general advancement in D.Q.

It would perhaps be surprising if there were a great advance in mental level within a few weeks of cessation of spasms, and it is of more relevance to know whether there is mental advancement over a long period, particularly when the child has been free from spasms and the E.E.G. has been normal for some time. We cannot yet answer this fully, but it is already clear that, in a minority of patients, whose spasms are arrested, a significant increase in development quotient has occurred. The D.Q.s of four patients have increased by more than 10 over the pre-treatment figure. Only two, however, have reached 80 or over, and can therefore be included in the normal range (Griffiths, 1954). It is the opinion of Sorel and Dusaucy-Bauloye (1958), Gastaut et al. (1959) and Low (1959) that mental improvement only occurs if treatment is started within a few weeks of the onset of spasms. Only one of our four patients who showed significant mental improvement was treated within one month of the onset. Six other patients treated within three months showed no improvement. There is therefore no evidence from our results that early treatment is necessarily important.

There is definite evidence that mental retardation is not an inevitable accompaniment of infantile spasms untreated with steroids (Burnett, Gibbs and Gibbs, 1958; Jeavons and Bower, 1961) and the question arises as to whether the treatment given to our patients played any part in the mental improvement. Only two patients have achieved normal or near-normal mentality as yet. In our series of 30 patients not treated with corticotrophin or prednisolone there were two patients who, although not assessed on the Griffiths scale, appeared to be mentally normal during the second year of life, and have subsequently remained so. There is, therefore, no proof from a comparison of the two series that mental improvement, when it occurs after hormone administration, is due to the treatment. We have recently observed three other patients whose spasms ceased spontaneously before treatment could be given. They are now, at 14, 17 and 22 months of age, within the normal range, having D.Q.s over 80 . On the other hand, the initial E.E.G. of C.1, the patient in the cryptogenic group who was treated within one month of onset and who now has a normal or near-normal mental level, was grossly chaotic (score 22; Fig. 1), whereas the initial scores of four of the five untreated normal patients were low $(4,5,4,2)$. Moreover, his mental regression at the onset was obviously greater than theirs. This might mean that without steroids he would have continued with spasms and an abnormal E.E.G. for some time and have remained mentally defective, but this is impossible to prove. (The fifth untreated patient who is now mentally normal had two hypsarrhythmic E.E.G.s (score 15) initially.) Several patients showed a slight tendency towards mental improvement after spasms had stopped, but again this cannot be ascribed to treatment, for such a tendency to improve occurred in the series of untreated patients.

Mechanism of Action of Corticotrophin and Adrenal Steroids. The mechanism is unknown. The following hypotheses are worth consideration, but it is admitted that there is as yet no proof of their validity.

(1) Correction of Faulty Enzymatic ProCESSES. Although a vague concept, some recent work suggests that there is in this syndrome a fault in cerebral biochemical processes. Cochrane (1959) has reported abnormal results when the tryptophan load test (Bessey, Adam and Hansen, 1957) was used in five patients with infantile spasms; pyridoxine produced mental improvement, stopped the spasms and subsequent tryptophan load tests gave normal results. We have therefore used the test in three of our patients before and during steroid treatment. In all three the results were abnormal before treatment and normal during treatment, when clinical and E.E.G. improvement had occurred. If these findings can be confirmed, it will be tempting to postulate that steroids act by accelerating the maturation of some biochemical process which is necessary for normal mental development and which inhibits epileptic discharges. The nature of the improvement affords some support for this concept. We have been impressed by the similarity between the pattern of clinical and E.E.G. improvement occurring in treated cases over a few weeks and that occurring in untreated cases over several years. In particular, the E.E.G. changes in the two groups are identical. Low (1958) and Armstrong (1959) have suggested that corticotrophin acts by accelerating maturation of enzyme systems.

(2) Changes IN THE INTRACEllulaR-ExTRACellular Electrolyte Ratios. It is known that the normal axon sheath excludes sodium from the nerve fibre and maintains a high intracellular potassium concentration; this state of affairs is temporarily reversed by the passage of a nerve impulse (Marshall, 1959). Possibly this pump action of the cell membrane is disturbed in epilepsy, and steroids restore its integrity, thus inhibiting the disordered electrical activity which is found particularly in infantile spasms. Evidence from 
animal experiments (Millichap, 1958) suggests that the epileptic threshold for febrile convulsions is lower when the intracellular potassium of the brain is low. We can offer no evidence to support this hypothesis but, unlike the first hypothesis, it would explain the fact that improvement occurs in the symptomatic as well as in the cryptogenic group and also the finding of clinical and E.E.G. improvement during corticotrophin administration in major and minor epilepsy in older children (Klein and Livingston, 1950).

(3) Anti-inflammatory Action. It has been suggested by Gastaut and Roger (1953) and Gibbs and Gibbs (1952) that this syndrome is due, at least in some cases, to encephalitis, allergic or otherwise. The beneficial effect of hormones would then be due to their anti-inflammatory action. However, pathological examination shows no evidence of encephalitis (Poser, 1959) and the improvement in cases where the disorder is due to other causes (perinatal brain damage, cerebral agenesis with absence of corpus callosum, and phenylketonuria) makes this hypothesis unsatisfactory.

(4) Correction OF Hypoglycaemia OR Low INTRACEllular Glucose. There was no demonstrable hypoglycaemia in any of our patients, nor did Low (1958) find any evidence of it in his cases. It might be argued that the hormones act by increasing the availability of glucose to the cell, but this again seems an unlikely explanation of the benefit which occurred in the symptomatic group.

Recommendations. Since spasms are controlled in nearly all cases regardless of aetiology, there is some justification for using corticotrophin or prednisolone in any patient with this disorder. However, the best long-term results are obtained in the cryptogenic group, and we would not necessarily recommend treatment of every patient in the symptomatic group owing to the high relapse rate in such patients and the evidence that mental improvement is unlikely.

Treatment should be given to any patient with the disorder who does not have a definite history of perinatal or prenatal brain injury and whose previous development has been normal or nearly so. There is a fair chance of stopping spasms permanently and we agree with Stamps et al. (1959) that it is difficult to predict which patients will respond. We have no proof from our trial that mental improvement, when it occurs, is due to the drugs, but there is no other treatment which seems as likely to bring it about. We recommend that treatment should be given as early as possible, although again we have as yet no proof that this is essential to achieve normal mentality. Certainly we cannot be satisfied with the results presented in this paper and we feel strongly that intensive efforts to diagnose and treat the condition earlier are needed.

We now prefer corticotrophin to prednisolone as the initial drug. However, it may be justifiable particularly where long-term treatment is needed, to follow the first course with prednisolone, which can be conveniently given at home. Dumermuth (1959) recommends intermittent hydrocortisone therapy for at least six months. The daily dose of corticotrophin should be at least 25 i.u., except possibly in the first three months of life, and it may be necessary to increase the dose if there is an inadequate response. The minimum length of treatment should be one month but improvement may not occur until after this period (Case C.9). We feel that the best method of assessing improvement is by the use of the E.E.G., and a normal or non-epileptic record during treatment should be the aim. It is not necessary to use our rather elaborate scoring system to recognize improvement, but it gives a more objective assessment. Ideally an E.E.G. should be taken twice weekly but a weekly assessment may suffice. Probably the drug should be continued at full dosage for two or three weeks after a normal E.E.G. has been obtained or all chaos has disappeared from the record. The dose may then be gradually reduced. Side effects of treatment were minor (moon-face and water retention) except in one child who developed cardiac failure.

\section{Summary}

Twenty-three children with infantile spasms were treated with corticotrophin or prednisolone for at least four weeks. Spasms ceased during treatment in 18 patients but recurred in 13 after treatment.

Some E.E.G. improvement occurred in all patients except one, and a non-epileptic record was achieved in nine, though relapse occurred in five of those whose spasms recurred. Eight were given a second course of treatment but seven again relapsed.

At the end of an average follow-up period of eight months, 11 patients had no spasms.

The effect of corticotrophin was similar to that of prednisolone, although, with the doses employed, corticotrophin appears preferable. No immediate mental improvement occurred, and only two cases eventually achieved a development quotient of 80 or more. Although the drugs had a temporary beneficial effect in both the symptomatic and cryptogenic groups, better results were achieved in the latter group. 
A comparison is made with a group of patients not treated with hormones and it is concluded that on the whole these drugs have a long-term beneficial effect on the spasms, whereas their effect on mentality is doubtful.

It is possible that under hormonal treatment there is an acceleration of the natural changes which occur with age. The mode of action is discussed and recommendations for treatment are made.

Thanks are due to the consultant physicians of the Children's Hospital and the consultant paediatricians of the Birmingham and Oxford Regions for allowing us to investigate and treat their patients; to Professor D. V. Hubble for encouragement and advice; to Dr. B. S. B. Wood for help with Griffiths testing, and for advice; and to Miss Doris Campbell and Mrs. S. Rickards for their patience and skill in the E.E.G. examination of these difficult patients.

\section{REFERENCES}

Armstrong, M. D. (1959). In Molecules and Mental Health, ed. F. A. Gibbs, p 169 Lippincott Philadelphia and Montreal.

Bessey, O. A., Adam, D. J. D. and Hansen, A. E. (1957). Intake of vitamin B6 and infantile convulsions: a first approximation of requirements of pyridoxine in infants. Pediatrics, 20, 33.

Burnett, L. L., Gibbs, E. L. and Gibbs, F. A. (1958). Prognosis in infantile spasms. Ibid., 21, 719 .

Cochrane, W. A. (1959). Unpublished report.
Cox, P. J. N. and Martin, E. (1959), Letter to the Editor: Infantile spasms and hypsarrhythmia. Lancet, 1, 1099.

Dumermuth, G. (1959). Uber die Blitz-Nick-Salaam-Krämpfe und ihre Behandlung mit ACTH und Hydrocortison. Vorläufige Mitteilung. Helv. paediat. Acta, 14, 250.

Gastaut, H. and Roger, A. (1953). Symposium sur les convulsions de l'enfance; étude électroencéphalographique des convulsions infantiles. Pédiatrie, 8, 603.

Saltiel, J., Raybaud, C., Pitot, M. and Meynadier, A. (1959). A propos du traitement par l'A.C.T.H. des encéphalites myocloniques de la première enfance avec dysrhythmie majeure (hypsarhythmia). Ibid., 14, 35

Gibbs, F. A. and Gibbs, E. L. (1952). Atlas of Electroencephalography, vol. 2, p. 25. Addison-Wesley Press, Cambridge, Mass.

Griffiths, R. (1954). The Abilities of Babies, p. 100. University of London Press, London.

Jeavons, P. M. and Bower, B. D. (1961). The natural history of infantile spasms. Arch. Dis. Childh., 36, 17.

Klein, R. and Livingston, S. (1950). The effect of adrenocorticotropic hormone in epilepsy. J. Pediat., 37, 733 .

Low, N. L. (1958). Infantile spasms with mental retardation. II. Treatment with cortisone and adrenocorticotropin. Pediatrics, 22, 1165.

(1959). Treatment of hypsarhythmia with A.C.T.H. and cortisone. In Molecules and Mental Health, ed. F. A. Gibbs, p. 124. Lippincott, Philadelphia and Montreal.

Marshall, J. (1959). Clinical Neurophysiology, p. 3. Blackwell, Oxford.

Millichap, J. G. (1958). The febrile seizure threshold in relation to maturation of brain water, electrolyte, and acid-base balance of newborn animals. A.M.A.J. Dis. Child., 96, 492.

Poser, C. M. (1959). Neuropathologic findings in three cases of infantile spasms. In Molecules and Mental Health, ed. F. A. Gibbs, p. 150. Lippincott, Philadelphia and Montreal.

Sorel, L. (1959). Treatment of hypsarhythmia with A.C.T.H. Ibid., p. 114 .

- and Dusaucy-Bauloye, A. (1958). A propos de 21 cas d'hypsarhythmia de Gibbs. Son traitement spectaculaire par l'ACTH. Acta neurol. psychiat. belg., 58, 130.

Stamps, F., Gibbs, E. L., Rosenthal, I. M. and Gibbs, F. A. (1959). Treatment of hypsarhythmia with A.C.T.H. J. Amer. med.Ass., 171, 408. 